\title{
Numerical simulation of the seismic behavior of building structures equipped with friction energy dissipators
}

\author{
S.T. De la Cruz ${ }^{\text {a }}$, F. López-Almansa ${ }^{\text {b,* }}$, S. Oller ${ }^{\text {c }}$ \\ ${ }^{a}$ Civil and Environmental Engineering Department, Universidad Autónoma de Ciudad Juárez, Av. Del Charro \# 450 Nte., 32310 Cd. Juarez, Mexico \\ ${ }^{\mathrm{b}}$ Architecture Structures Department, Technical University of Catalonia, Avda. Diagonal 649, 08028 Barcelona, Spain \\ ${ }^{\mathrm{c}}$ Strength of Materials and Engineering Structures Department, Technical University of Catalonia, Gran Capitán s/n, 08034 Barcelona, Spain
}

Received 7 November 2005; accepted 8 August 2006

Available online 13 November 2006

\begin{abstract}
This paper presents a new algorithm to simulate the seismic response of $N$-story building frames incorporating friction energy dissipators; a device per floor is considered. The frames with the dissipators are described by 2D lumped masses models with two degrees of freedom per floor, namely the horizontal displacements of the main structure and of the dissipators. The proposed algorithm consists of a modification of the linear acceleration method; the main innovation consists of checking at each calculation instant the sliding or sticking condition at each floor, hence, the number of "active" degrees of freedom changes continuously, ranging in between $N$ (there is sticking condition at every dissipator) and $2 N$ (there is sliding condition at every dissipator). Some results given by this algorithm are compared to experimental results from ad-hoc testing and to numerical results obtained with the ADINA software package. In both cases, agreement is satisfactory while the proposed method is more computationally efficient.
\end{abstract}

(C) 2006 Elsevier Ltd. All rights reserved.

Keywords: Energy dissipators; Friction; Contact analysis; Dynamics of structures; Seismic forces; Earthquake resistant structures; Passive control; Numerical simulation; Non-linear analysis

\section{Introduction}

Reducing the response of buildings to strong earthquakes is of great concern for structural engineers to prevent big damage and structural collapse. The traditional approach consists of designing ductile constructions and dissipating the input energy through big strains in the main structure; but this causes damage and/or might lead to over-conservative and impractical designs. Conversely, in the 1970s the use of energy dissipation devices not belonging to the main gravity load-resisting system was suggested $[26,14]$. These devices are specifically designed to absorb the input energy and can be easily replaced after strong excitations. As the structure remains basically elastic, resid-

\footnotetext{
* Corresponding author. Tel.: +3493 4016316; fax: +34934016320.

E-mail address: francesc.lopez-almansa@upc.edu (F. López-Almansa).
}

ual displacements are then released. Fig. 1 shows three sketches of a moment resisting frame (belonging to a multi-story building) with energy dissipators.

The systems depicted in Fig. 1 are intended to prevent excessive sideway oscillations for horizontal support motions (mostly earthquakes); every time inter-story drifts are generated, energy is dissipated through big strains, distortions or displacements in the devices. Fig. 1(a) represents a solution where dissipators are placed in the connections between the main structure and the bracing system (it is sketched as chevron braces, but other systems e.g. detached concrete or masonry walls - can be equally used). Fig. 1(b) displays dissipators connected to split (sliding) diagonal braces while Fig. 1(c) shows devices connected to four half-braces. Looking for vertical regularity, at Fig. 1 all the floors have devices incorporated.

General non-linear (numerical) models are non-suitable for describing the dynamic behavior of buildings 

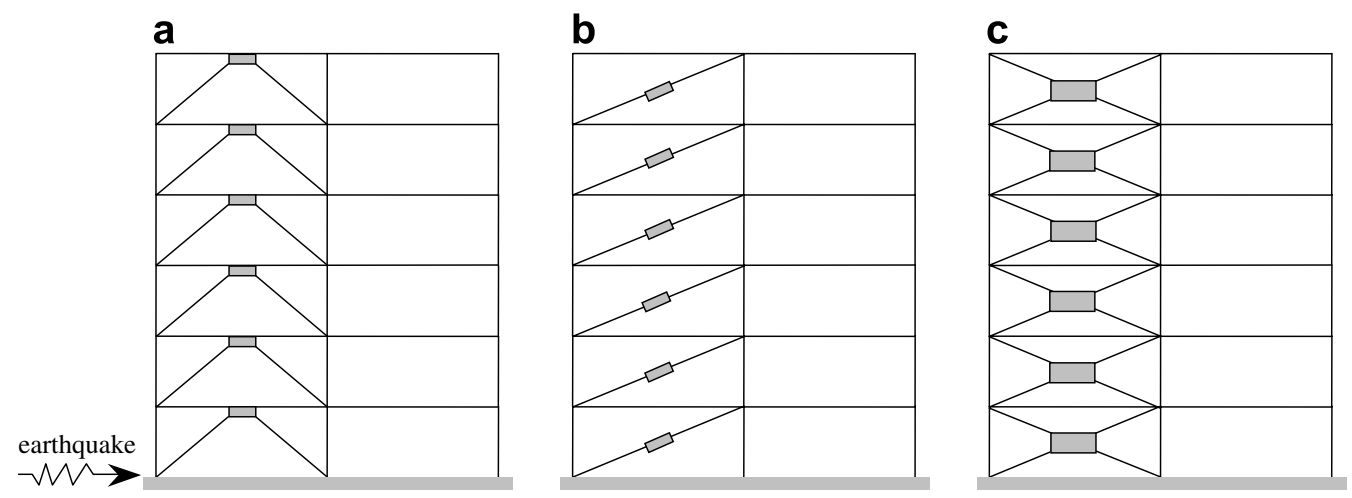

Fig. 1. Building frames equipped with energy dissipators.

\begin{abstract}
incorporating energy dissipators because the main structure is supposed to remain elastic while the non-linearities are left to dissipators and also because the coexistence of elements with extremely different stiffness parameters (the dissipators themselves can be significantly more flexible than the main structure and the bracing system) could lead to numerical instability and to a certain lack of accuracy. As discussed next, the numerical simulation of friction dis-
\end{abstract}

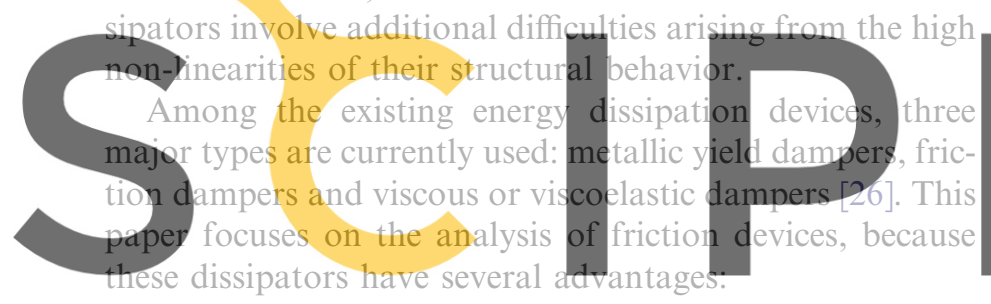

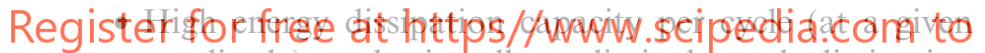
amplitude) and virtually unlimited total dissipation capacity (mainly limited by the wearing of the sliding surfaces).

- Controllable friction force (through the transversal prestressing force).

- Insensitivity to the number of loading cycles and no fatigue effects. As there are virtually no strains, the only relevant time effect is the change of the friction coefficient (e.g. due to corrosion and wearing of the sliding surfaces).

Conversely, friction dissipators exhibit some potentially relevant disadvantages:

- The energy dissipated per cycle is only proportional to the maximum displacement (see Fig. 2) instead of the square of this displacement, as in the case of viscous damping. This fact can be relevant for sudden pulses and for inputs stronger than those expected. Moreover, resonance peaks cannot be properly cut [17].

- Due to the frequent and sudden changes in the stickingsliding conditions, high frequency response can be generated. This is relevant for human comfort and for non-structural elements safety because important accelerations might appear.

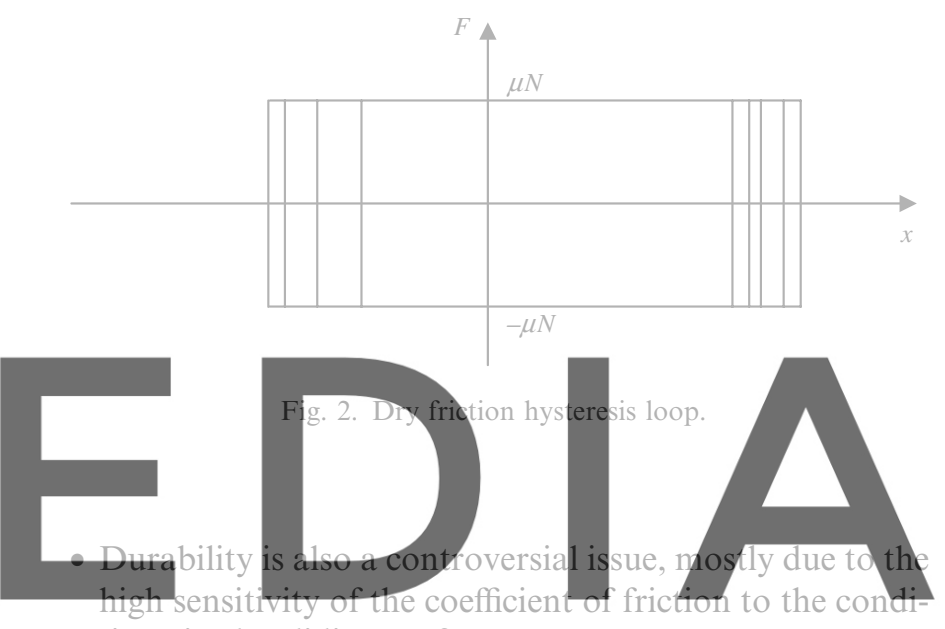

tions in the sliding surfaces.

download the version without the watermark On the other hand, the dynamic behavior of friction dissipators is highly non-linear (every time the sense of sliding reverts, the friction force changes suddenly from $\mu N$ to $-\mu N$, see Fig. 2) and the modeling of sliding is complicated, hence, the numerical simulation is a challenging issue. A number of ad-hoc models have been developed, such as the one considered in the ADINA software package [3]. Some other codes simulate friction through equivalent bilinear hysteretic behavior (typical of yielding devices); in fact, this approach was used previously by one of the authors [12]. However, there are three major differences: (1) yielding devices are usually quite flexible while the initial stiffness of the sliding ones is virtually infinite, (2) in friction dissipators plastic hardening is negligible and (3) by assuming bilinear behavior, only "parallelogramshaped" hysteresis loops can be considered while the algorithm proposed here can reproduce more complicated (realistic) hysteresis loops with many stick-slide changes. These aspects are more deeply studied at Refs. [8,9]. In that paper, some comparisons between the results obtained with bilinear [5] and friction models show that the responses are quite similar but relevant differences in the amount of input energy are still found. This certain lack of accurate and reliable numerical models causes some controversy about some subjects such as overall seismic efficiency, reliability, 
introduction of high frequencies in the response [15] and seismic behavior under near-fault pulses [24]. Moreover, no specific design guidelines for friction dissipators have been reported.

A variety of friction devices have been proposed for structural energy dissipation $[28,6,20,13,26,15,24]$. These devices differ in their mechanical complexity and in the materials used in the sliding surfaces but if it is assumed that the friction coefficient is non-velocity-dependent, that the static and dynamic friction coefficients are equal and that the pre-stressing force is constant, almost all of them generate rectangular hysteresis loops (typical of Coulomb friction) as the one depicted in Fig. 2.

The main purpose of this paper is to propose a new algorithm to simulate the seismic behavior of building frames equipped with friction energy dissipators, such as the system described in Fig. 1. The stability, accuracy and overall performance (e.g. CPU time and memory requirement) of the proposed model are compared to those of the ADINA commercial software package. The hysteresis loops of the dissipators are rectangular, as shown in Fig. 2.

The proposed model is also useful to simulate the dynamic behavior of buildings with friction isolators (base iselation) or excited by other dynamic inputs
This work belongs to a bigger research project whose
purpose is to assess the efficiency of friction dissipators
for sgismic protection of buildings. This rosearch in olves
experiments and a parametric numerical analysis [9]. Some
of these numerical results are compared to those from the proposed algorithm to yield additional information about Registepufor free elethittps//www.scipedia.com to

The next section describes the general dry friction theory as used in the algorithm presented in this paper.

\section{Friction constitutive model}

This section describes the static behavior of a single friction dissipator (see Fig. 1) [21]. Fig. 3 depicts the mechanical model of the contact problem.
In Fig. 3, $x$ and $x^{\prime}$ are, respectively, the horizontal displacements of the main frame and of the dissipative device. The coefficient $k^{\prime}$ represents the stiffness of the bracing system supporting the dissipator.

At a single point belonging to the contact surface, the limit condition for the unidirectional constitutive model based on the classical Coulomb's Law - [25] is

$$
f\left(F, u_{N}\right) \equiv g\left(F, u_{N}\right)=|F|-\langle\mu N\rangle=|F|-\left\langle\mu K_{N} u_{N}\right\rangle \leqslant 0
$$

where $f(F)$ and $g(F)$ are the plastic yielding limit function and the plastic potential, respectively. $F$ is the friction force between the dissipator and the structure, $\mu$ is the dry static friction coefficient $\left(\mu=\tan \phi^{\text {fric }}\right.$ where $\phi^{\text {fric }}$ is the rugosity angle) and $N$ is the prestressing force - acting normally to the contact surface - given by $N=K_{N} u_{N}$, where $K_{N}$ and $u_{N}$ are the penetration stiffness and displacement, respectively.

If during the calculation process, this limit condition is not fulfilled, it means that there is sliding $\left(\dot{x} \neq \dot{x}^{\prime}\right)$ and the relative displacement $x-x^{\prime}$ between the dissipator and the structure is defined by the classical plasticity theory through the normality rule,

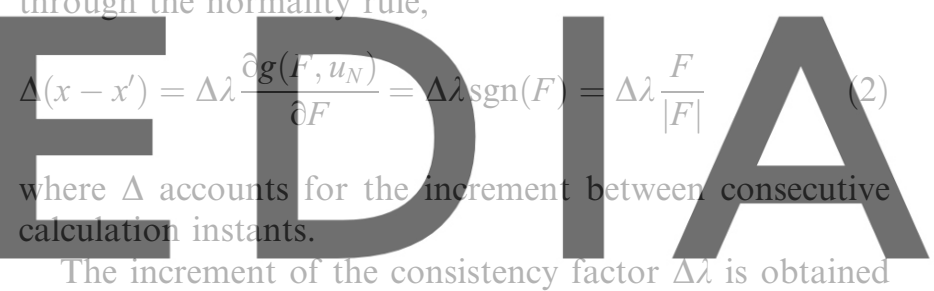

by imposing the plastic consistency condition:

download the version without the watermark

$\Delta f\left(F, u_{N}\right)=0=\frac{\partial f}{\partial F} \Delta F+\frac{\partial f}{\partial u_{N}} \Delta u_{N}$

$$
=\operatorname{sgn}(F) k^{\prime} \Delta x^{\prime}-\mu\left\langle\frac{u_{N}}{\left|u_{N}\right|}\right\rangle k^{\prime} \Delta u_{N}
$$

By substituting the relative displacement $x-x^{\prime}$ into this last equation, the plastic consistency factor (or Lagrange multiplier) is obtained:

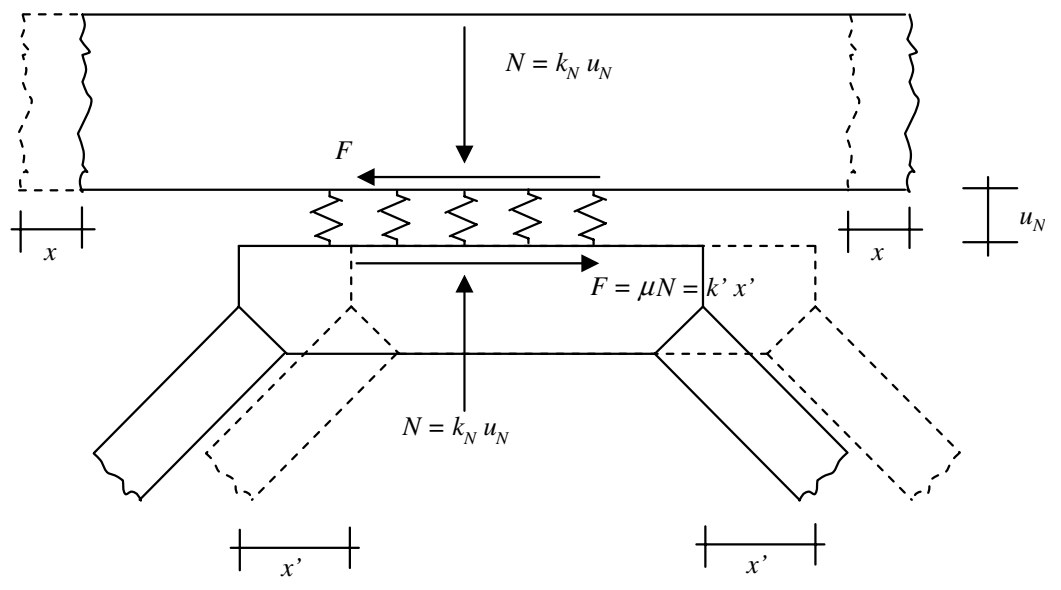

Fig. 3. Interaction forces between the main frame and a friction dissipator. 


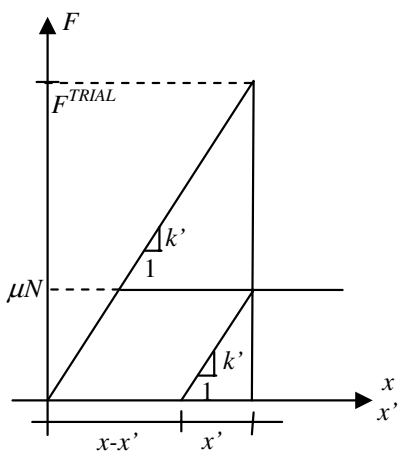

Fig. 4. Frictional device static model.

$$
0=\operatorname{sgn}(F) k^{\prime}[\Delta x-\Delta \lambda \operatorname{sgn}(F)]-\mu\left\langle\frac{u_{N}}{\left|u_{N}\right|}\right\rangle k_{N} \Delta u_{N}
$$

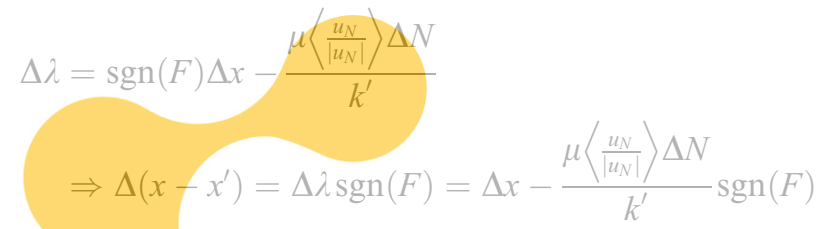

Fig. 4 shows the trial-and-error constitutive behavior of the

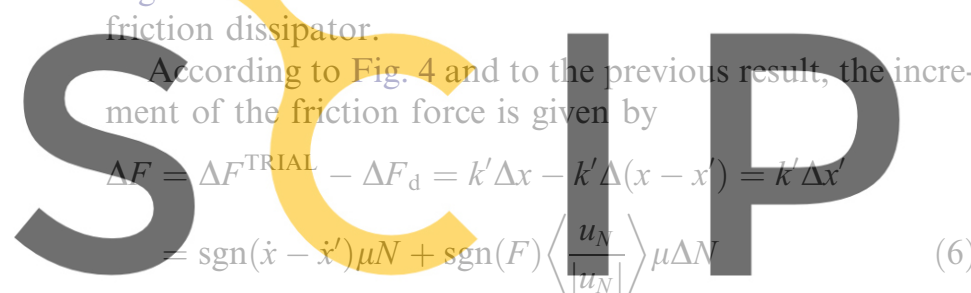

These results yield the tangent stiffness matrix related to the

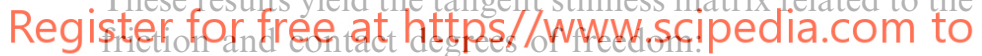

$$
\left(\begin{array}{c}
\Delta N \\
\Delta F
\end{array}\right)=\left(\begin{array}{cc}
k^{\prime} & 0 \\
\operatorname{sgn}(F) \mu\left\langle\frac{u_{N}}{\left|u_{N}\right|}\right\rangle k_{N} & 0
\end{array}\right)\left(\begin{array}{c}
\Delta u_{N} \\
\Delta x
\end{array}\right)
$$

If the prestressing force $N$ is constant $(\Delta N=0)$, the contact degree of freedom $u_{N}$ is not required since $\Delta u_{N}=0$. In such a case only stiffness coefficients given by $\operatorname{sgn}(F) \mu\left\langle\frac{u_{N}}{\left|u_{N}\right|}\right\rangle k_{N}$ have to be incorporated to the corresponding degrees of freedom.

\section{Equations of motion}

In this section a multi-story building (with a symmetry plan) incorporating friction dissipators on each floor (as described in Fig. 1) is considered. The number of floors is denoted by $N$. The excitation consists of a seismic motion; the case of lateral loading can be similarly analyzed as shown next.

As there is symmetry, the structure is modelled as a $2 \mathrm{D}$ frame. The degrees of freedom are selected as the relative horizontal displacements of floors $\left(x_{1}, \ldots, x_{i}, \ldots, x_{N}\right)$ and dissipators $\left(x_{1}^{\prime}, \ldots, x_{i}^{\prime}, \ldots, x_{N}^{\prime}\right)$. If a dissipator is stuck (this situation is termed as sticking condition) then $\dot{x}_{i}^{\prime}=\dot{x}_{i}$; otherwise (when sliding occurs, situation is termed as sliding condition) such velocities are different. Consequently, the number of active degrees of freedom changes continuously, ranging between $N$ (all the dissipators are stuck) and $2 N$ (all the dissipators slide simultaneously).

The proposed model can be used to describe the dynamic behavior of any 2D structure. As an illustrative example to derive the equations of motion, the case of a shear frame is considered next. As stated previously, the maximum number of degrees of freedom is $2 N$. The $2 N$ equations are

$$
\begin{aligned}
& m_{1}\left(\ddot{x}_{1}+\ddot{x}_{\mathrm{g}}\right)+c_{1} \dot{x}_{1}+k_{1} x_{1}-c_{2}\left(\dot{x}_{2}-\dot{x}_{1}\right)-k_{2}\left(x_{2}-x_{1}\right) \\
& \quad-c_{2}^{\prime}\left(\dot{x}_{2}^{\prime}-\dot{x}_{1}\right)-k_{2}^{\prime}\left(x_{2}^{\prime}-x_{1}\right)=-F_{1} \\
& m_{1}^{\prime}\left(\ddot{x}_{1}^{\prime}+\ddot{x}_{\mathrm{g}}\right)+c_{1}^{\prime} \dot{x}_{1}^{\prime}+k_{1}^{\prime} x_{1}^{\prime}=F_{1} \\
& m_{2}\left(\ddot{x}_{2}+\ddot{x}_{\mathrm{g}}\right)+c_{2}\left(\dot{x}_{2}-\dot{x}_{1}\right)+k_{2}\left(x_{2}-x_{1}\right)-c_{3}\left(\dot{x}_{3}-\dot{x}_{2}\right) \\
& \quad-k_{3}\left(x_{3}-x_{2}\right)-c_{3}^{\prime}\left(\dot{x}_{3}^{\prime}-\dot{x}_{2}\right)-k_{3}^{\prime}\left(x_{3}^{\prime}-x_{2}\right)=-F_{2} \\
& m_{2}^{\prime}\left(\ddot{x}_{2}^{\prime}+\ddot{x}_{\mathrm{g}}\right)+c_{2}^{\prime}\left(\dot{x}_{2}^{\prime}-\dot{x}_{1}\right)+k_{2}^{\prime}\left(x_{2}^{\prime}-x_{1}\right)=F_{2}
\end{aligned}
$$

$m_{i}\left(\ddot{x}_{i}+\ddot{x}_{\mathrm{g}}\right)+c_{i}\left(\dot{x}_{i}-\dot{x}_{i-1}\right)+k_{i}\left(x_{i}-x_{i-1}\right)-c_{i+1}\left(\dot{x}_{i+1}-\dot{x}_{i}\right)$

$-k_{i+1}\left(x_{i+1}-x_{i}\right)-c_{i+1}^{\prime}\left(\dot{x}_{i+1}^{\prime}-\dot{x}_{i}\right)-k_{i+1}^{\prime}\left(x_{i+1}^{\prime}-x_{i}\right)=-F$ $m_{i}^{\prime}\left(\ddot{x}_{i}^{\prime}+\ddot{x}_{\mathrm{g}}\right)+c_{i}^{\prime}\left(\dot{x}_{i}^{\prime}-\dot{x}_{i-1}\right)+k_{i}^{\prime}\left(x_{i}^{\prime}-x_{i-1}\right)=F_{i}$

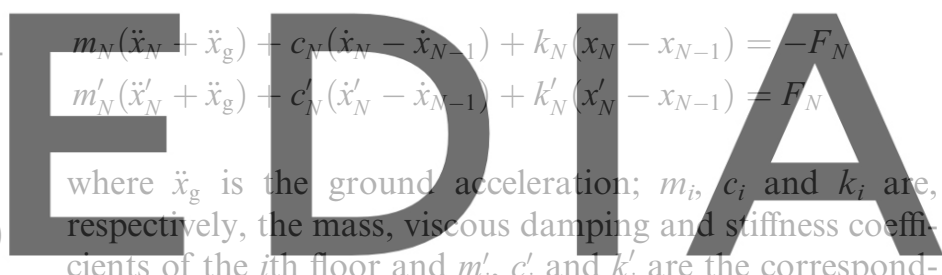
ing values for the bracing connecting the dissipator and the

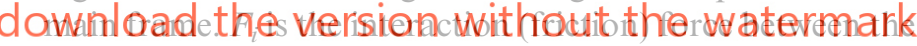
dissipator and the structure satisfying Eq. (1).

The values of $F_{i}$ are limited by the corresponding friction coefficients $\mu_{i}$ and prestressing forces $N_{i}$ :

$\left|F_{i}\right| \leqslant \mu_{i} N_{i}$

This condition can be easily modified to account for the case when the maximum and minimum values of $\mu_{i} N_{i}$ are different: $\left(\mu_{i} N_{i}\right)_{\min } \leqslant F_{i} \leqslant\left(\mu_{i} N_{i}\right)_{\max }$; this capacity is used in the following to simulate experimental results.

The set of $2 N$ equations of motion can be divided into two subsets dealing, respectively, with the main structure and the dissipators:

$$
\begin{aligned}
\left(\begin{array}{cccc}
m_{1} & 0 & & \\
0 & m_{2} & & \\
& & \ddots & \\
& & m_{N}
\end{array}\right)\left(\begin{array}{c}
\ddot{x}_{1} \\
\ddot{x}_{2} \\
\vdots \\
\ddot{x}_{N}
\end{array}\right) \\
+\left(\begin{array}{cccc}
c_{1}+c_{2}+c_{2}^{\prime} & -c_{2} & & \\
-c_{2} & c_{2}+c_{3}+c_{3}^{\prime} & \ddots & \\
& & \ddots & -c_{N} \\
& & -c_{N} & c_{N}
\end{array}\right)\left(\begin{array}{c}
\dot{x}_{1} \\
\dot{x}_{2} \\
\vdots \\
\dot{x}_{N}
\end{array}\right)
\end{aligned}
$$




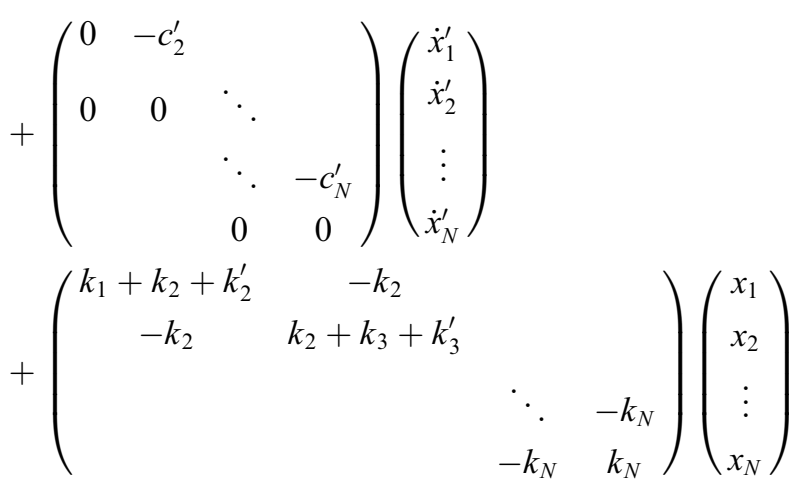
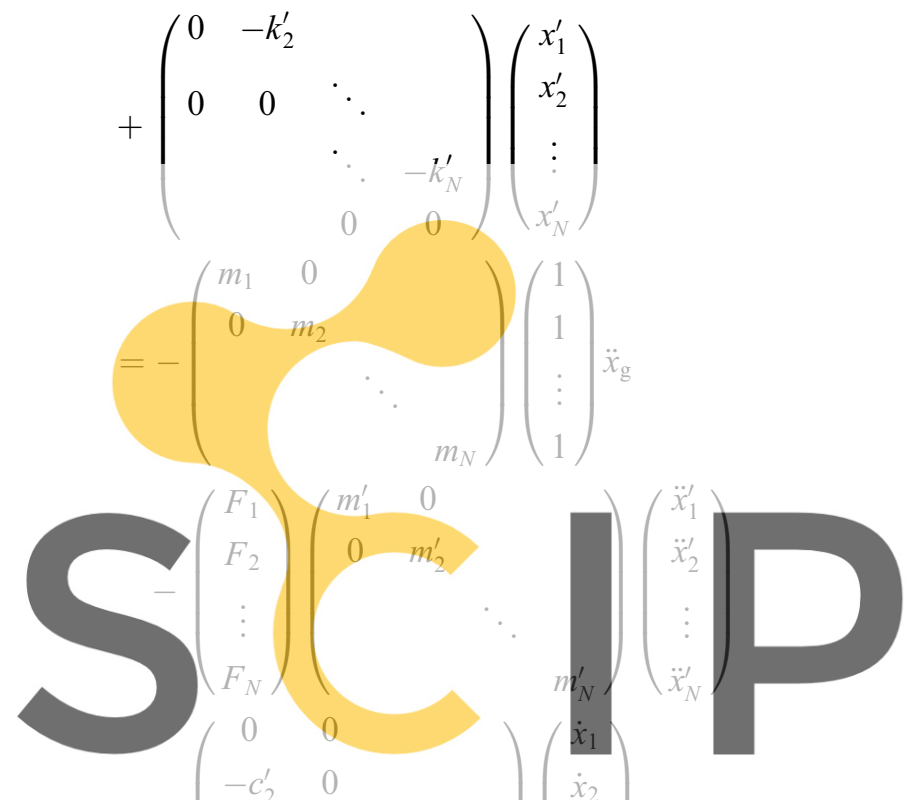

Register for free at https//www.scipedia.com to
These two sets of equations can be written in matrix form as

$$
\begin{aligned}
& \mathbf{M}^{\mathrm{ss}} \ddot{\mathbf{x}}^{\mathrm{s}}+\mathbf{C}^{\mathrm{ss}} \dot{\mathbf{x}}^{\mathrm{s}}+\mathbf{C}^{\mathrm{sd}} \dot{\mathbf{x}}^{\mathrm{d}}+\mathbf{K}^{\mathrm{ss}} \mathbf{x}^{\mathrm{s}}+\mathbf{K}^{\mathrm{sd}} \mathbf{x}^{\mathrm{d}}=-\mathbf{M}^{\mathrm{ss}} \ddot{\mathbf{r}}_{\mathrm{g}}-\mathbf{F} \\
& \mathbf{M}^{\mathrm{dd}} \ddot{\mathbf{x}}^{\mathrm{d}}+\left(\mathbf{C}^{\mathrm{sd}}\right)^{\mathrm{T}} \dot{\mathbf{x}}^{\mathrm{s}}+\mathbf{C}^{\mathrm{dd}} \dot{\mathbf{x}}^{\mathrm{d}} \\
& \quad+\left(\mathbf{K}^{\mathrm{sd}}\right)^{\mathrm{T}} \mathbf{x}^{\mathrm{s}}+\mathbf{K}^{\mathrm{dd}} \mathbf{x}^{\mathrm{d}}=-\mathbf{M}^{\mathrm{dd}} \ddot{\mathbf{r}}_{\mathrm{g}}+\mathbf{F}
\end{aligned}
$$

Superindexes s and $\mathrm{d}$ account for structure and for dissipators, respectively: $\mathbf{x}^{\mathrm{s}}=\left(x_{1}, \ldots, x_{i}, \ldots, x_{N}\right)^{\mathrm{T}}$ and $\mathbf{x}^{\mathrm{d}}=$ $\left(x_{1}^{\prime}, \ldots, x_{i}^{\prime}, \ldots, x_{N}^{\prime}\right)^{\mathrm{T}}$. The second (10) will be in turn split into two subsets denoted with subindexes sl (sliding) and st (sticking); the degrees of freedom involved in each of them vary from instant to instant as the sliding conditions in the dissipators change. If the input consists of driving forces (acting on every floor), the right hand side members of Eqs. 9 and 10 have to be replaced by $\mathbb{P}-\mathbb{F}$ and $\mathbb{F}$, respectively, where vector $\mathbf{P}$ contains the excitation forces.

\section{Numerical solution of the equations of motion}

This section describes the numerical solution of Eqs. (9) and (10). The main difficulties arise from the fact that both equations are non-linear and are coupled through the inter-

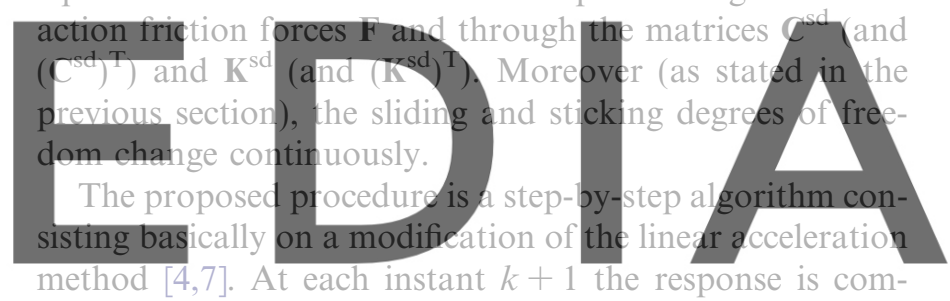

puted from the one at previous instant $k$ by three nested

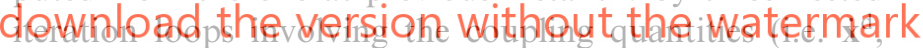
$\mathbf{x}^{\mathrm{d}}, \dot{\mathbf{x}}^{\mathrm{s}}, \mathrm{x}^{\mathrm{s}}$ and $\mathbf{F}$ ) and the estimated accelerations at step $k+1\left(\ddot{\mathbf{x}}_{k+1}^{* *}\right.$ and $\left.\ddot{\mathbf{x}}_{k+1}^{\mathrm{d} *}\right)$. The main innovation consists of checking at each calculation instant the sliding or sticking condition at each floor, hence, the number of "active" degrees of freedom changes continuously, ranging in between $N$ (there is sticking condition at every dissipator) and $2 N$ (there is sliding condition at every dissipator).

This iterative process initially assumes that the sliding conditions in the dissipators at instant $k$ are kept for instant $k+1$. A set of values of $\ddot{\mathbf{x}}_{k+1}^{\text {s* }}$ for $\left(\ddot{\mathbf{x}}_{k+1}^{\mathrm{s}}\right.$ ), ${ }_{\mathrm{sl}} \ddot{\mathbf{x}}_{k+1}^{\mathrm{d} *}$ (for ${ }_{\mathrm{sl}} \ddot{\mathbf{x}}_{k+1}^{\mathrm{d}}$ ) and ${ }_{\mathrm{st}} \mathbf{F}_{k+1}^{*}$ (for ${ }_{\text {st }} \mathbf{F}_{k+1}$ ) are assumed (usually $\ddot{\mathbf{x}}_{k+1}^{* * 1}=\ddot{\mathbf{x}}_{k}^{\mathrm{s}},{ }_{\mathrm{sl}} \ddot{\mathbf{x}}_{k+1}^{\mathrm{d} *}{ }_{\mathrm{sl}} \ddot{\mathbf{x}}_{k}^{\mathrm{d}}$ and ${ }_{\mathrm{st}} \mathbf{F}_{k+1}^{*}={ }_{\mathrm{st}} \mathbf{F}_{k}$ ). The remaining accelerations ${ }_{\mathrm{st}} \ddot{\mathbf{x}}_{k+1}^{\mathrm{d}}$ and forces ${ }_{\mathrm{sl}} \mathbf{F}_{k+1}$ are considered to be equal to the corresponding values in $\ddot{\mathbf{x}}_{k+1}^{s}$ and to the corresponding $\operatorname{sgn}\left(\dot{x}_{i}-\dot{x}_{i}^{\prime}\right) \mu_{i} N_{i}$, respectively. As stated in the previous paragraph, the proposed algorithm consists of three nested iteration loops; these iterations are performed with respect to $\ddot{\mathbf{x}}_{k+1}^{s},{ }_{\text {st }} \mathbf{F}_{k+1}$ and ${ }_{\mathrm{sl}} \ddot{\mathbf{x}}_{k+1}^{\mathrm{d}}$, respectively.

The interpolation criterion considered in the linear acceleration algorithm $[4,7]$ yields

$$
\begin{aligned}
& \mathbf{x}_{k+1}^{\mathrm{s}}=\mathbf{x}_{k}^{\mathrm{s}}+\Delta t \dot{\mathbf{x}}_{k}^{\mathrm{s}}+\frac{(\Delta t)^{2}}{6}\left(2 \ddot{\mathbf{x}}_{k}^{\mathrm{s}}+\ddot{\mathbf{x}}_{k+1}^{\mathrm{s} *}\right) \\
& \dot{\mathbf{x}}_{k+1}^{\mathrm{s}}=\dot{\mathbf{x}}_{k}^{\mathrm{s}}+\frac{\Delta t}{2}\left(\ddot{\mathbf{x}}_{k}^{\mathrm{s}}+\ddot{\mathbf{x}}_{k+1}^{\mathbf{s}^{*}}\right)
\end{aligned}
$$


$\mathbf{x}_{k+1}^{\mathrm{d}}=\mathbf{x}_{k}^{\mathrm{d}}+\Delta t \dot{\mathbf{x}}_{k}^{\mathrm{d}}+\frac{(\Delta t)^{2}}{6}\left(2 \ddot{\mathbf{x}}_{k}^{\mathrm{d}}+\ddot{\mathbf{x}}_{k+1}^{\mathrm{d} *}\right)$

$\dot{\mathbf{x}}_{k+1}^{\mathrm{d}}=\dot{\mathbf{x}}_{k}^{\mathrm{d}}+\frac{\Delta t}{2}\left(\ddot{\mathbf{x}}_{k}^{\mathrm{d}}+\ddot{\mathbf{x}}_{k+1}^{\mathrm{d} *}\right)$

The numerical formulation of the slide-stick condition in the $i$ th dissipator (8) is described next [21,2]. As stated previously, it is initially assumed that the condition for the previous instant $k$ holds. Hence, two possibilities must be considered:

1. If there was sticking at the previous instant $k$, the computed value $\left|F_{i}\right|_{k+1}$ is compared with $\mu_{i} N_{i}$; if $\left|F_{i}\right|_{k+1} \geqslant$ $\mu_{i} N_{i}$ there is sliding and therefore $\left(F_{i}\right)_{k+1}=\operatorname{sgn}$ $\left(\dot{x}_{i}-\dot{x}_{i}^{\prime}\right)_{k+1} \mu_{i} N_{i}$; conversely, if $\left|F_{i}\right|_{k+1}<\mu_{i} N_{i}$ there is sticking and $\left(\dot{x}_{i}-\dot{x}_{i}^{\prime}\right)_{k+1}=0$

2. If there was sliding at the previous instant $k$, the value of the relative velocity $\left(\dot{x}_{i}-\dot{x}_{i}^{\prime}\right)_{k+1}$ is computed; if $\left(\dot{x}_{i}-\dot{x}_{i}^{\prime}\right)_{k}\left(\dot{x}_{i}-\dot{x}_{i}^{\prime}\right)_{k+1}>0$ this condition holds (no change in the relative motion direction); on the other hand, if $\left(\dot{x}_{i}-\dot{x}_{i}^{\prime}\right)_{k}\left(\dot{x}_{i}-\dot{x}_{i}^{\prime}\right)_{k+1} \leqslant 0$ there is sticking and it is assumed that $\left(\dot{x}_{i}-\dot{x}_{i}^{\prime}\right)_{k+1}=0$. In fact, the fulfillment of the inequality $\left(\dot{x}_{i}-\dot{x}_{i}^{\prime}\right)_{k}\left(\dot{x}_{i}-\dot{x}_{i}^{\prime}\right)_{k+1} \leqslant 0$ could mean that. rather than sticking, the direction of the motion has

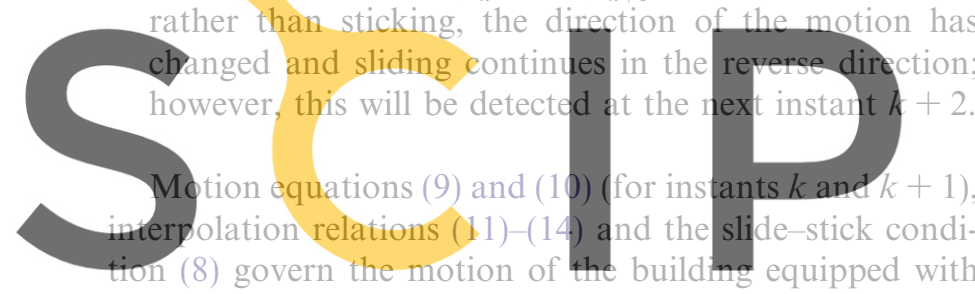

the friction dissipators. The three nested iteration loops

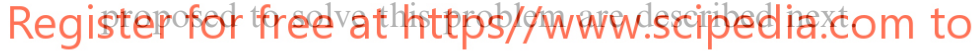

- First iteration loop. This is the inner loop. Structure displacements $\mathbf{x}_{k+1}^{\mathrm{s}}$ and velocities $\dot{\mathbf{x}}_{k+1}^{\mathrm{s}}$ are computed from (11) and (12) assuming that $\ddot{\mathbf{x}}_{k+1}^{s}=\ddot{\mathbf{x}}_{k+1}^{s}$ (initially $\ddot{\mathbf{x}}_{k+1}^{s}$ is taken equal to $\ddot{\mathbf{x}}_{k}^{s}$ ). In the dissipators that do not slide, displacements ${ }_{s t} \mathbf{x}_{k+1}^{\mathrm{d}}$ and velocities ${ }_{\text {st }} \dot{\mathbf{x}}_{k+1}^{\mathrm{d}}$ are equal to ${ }_{\mathrm{st}} \mathbf{x}_{k}^{\mathrm{d}}+\left({ }_{\mathrm{st}} \mathbf{x}_{k+1}^{\mathrm{s}}-{ }_{\mathrm{st}} \mathbf{x}_{k}^{\mathrm{s}}\right)$ and ${ }_{\mathrm{st}} \dot{\mathbf{x}}_{k+1}^{\mathrm{s}}$, respectively. In the sliding dissipators the displacements ${ }_{s \mathbf{l}} \mathbf{x}_{k+1}^{\mathrm{d}}$ and velocities ${ }_{s 1} \dot{\mathbf{x}}_{k+1}^{\mathrm{d}}$ are computed from (13) and (14), respectively, by taking ${ }_{s \mathbf{l}} \ddot{\mathbf{x}}_{k+1}^{\mathrm{d} *}={ }_{\mathrm{sl}} \ddot{\mathbf{x}}_{k}^{\mathrm{d}}$. Now $\ddot{\mathbf{x}}_{k+1}^{\mathrm{s}}$ is computed from (9) (for instant $k+1$ ). If $\ddot{\mathbf{x}}_{k+1}^{s} \neq \ddot{\mathbf{x}}_{k+1}^{s *}$ (with a prescribed tolerance $\varepsilon_{a}$ ) this procedure is repeated by taking $\ddot{\mathbf{x}}_{k+1}^{s *}=\ddot{\mathbf{x}}_{k+1}^{\mathrm{s}}$ without making any changes in the sliding conditions (dissipators keep their sliding condition). Once convergence is reached (i.e. $\left\|\ddot{\mathbf{x}}_{k+1}^{s}-\ddot{\mathbf{x}}_{k+1}^{s *}\right\| \leqslant \varepsilon_{a}$ ), iterations are stopped and Eq. (9) is fulfilled.

- Second iteration loop. This is the intermediate loop. In the sliding dissipators friction forces ${ }_{\mathrm{sl}} \mathbf{F}_{k+1}$ are known (i.e. $\left.\left(F_{i}\right)_{k+1}=\operatorname{sgn}\left(\dot{x}_{i}-\dot{x}_{i}^{\prime}\right)_{k+1} \mu_{i} N_{i}\right)$. The friction forces ${ }_{\text {st }} \mathbf{F}_{k+1}$ in the presumedly stuck dissipators are computed from the corresponding equations in (10). The components that are bigger than the corresponding sliding threshold $\mu_{i} N_{i}$ are set equal to that value and all of them are compared to the previously assumed values ${ }_{\mathrm{st}} \mathbf{F}_{k+1}^{*}$. If they are different (with a prescribed tolerance $\varepsilon_{f}$ ), the new values of ${ }_{\mathrm{st}} \mathbf{F}_{k+1}^{*}$ are set equal to the calculated forces ${ }_{\text {st }} \mathbf{F}_{k+1}$. Then, a new set of values for the structural acceleration $\ddot{\mathbf{x}}_{k+1}^{\mathrm{s}}$ is computed from (9) and it is replaced in (11) and (12) to get updated values of $\mathbf{x}_{k+1}^{\mathrm{s}}$ and $\dot{\mathbf{x}}_{k+1}^{\mathrm{s}}$ (as the loops are nested, it is necessary to return to the first loop). This procedure is repeated until ${ }_{s t} \mathbf{F}_{k+1}={ }_{\text {st }} \mathbf{F}_{k+1}^{*}$ (i.e. $\left.\left\|_{\mathrm{st}} \mathbf{F}_{k+1}-{ }_{\text {st }} \mathbf{F}_{k+1}^{*}\right\| \leqslant \varepsilon_{f}\right)$. Once this convergence is reached, Eq. (9) and those in (10) corresponding to the stuck dissipators are fulfilled.

- Third iteration loop. This is the outer loop. Once the convergence in ${ }_{\mathrm{st}} \mathbf{F}_{k+1}$ is achieved in the previous loop, then the accelerations ${ }_{s 1} \ddot{\mathbf{x}}_{k+1}^{\mathrm{d}}$ are computed from the corresponding equations in (10). If ${ }_{\text {sl }} \ddot{\mathbf{x}}_{k+1}^{\mathrm{d}} \neq{ }_{\mathrm{sl}} \ddot{\mathbf{x}}_{k+1}^{\mathrm{d} *}$ (with a prescribed tolerance $\left.\varepsilon_{a}\right)$ the current values of ${ }_{\text {sl }} \ddot{\mathbf{x}}_{k+1}^{\mathrm{d} *}$ are set equal to ${ }_{\text {sl}} \ddot{\mathbf{X}}_{k+1}^{\mathrm{d}}$. After this, new values of the displacements ${ }_{\mathrm{s} 1} \mathbf{X}_{k+1}^{\mathrm{d}}$ and velocities ${ }_{s 1} \dot{\mathbf{X}}_{k+1}^{\mathrm{d}}$ are computed from (11) and (12) and the accelerations $\ddot{\mathbf{x}}_{k+1}^{s}$ are calculated from (9). These values are used as the new approximations of the acceleration vector $\ddot{\mathbf{x}}_{k+1}^{s *}$ (again, the calculation process goes back to the first loop). The procedure stops when ${ }_{s \mathbf{l}} \ddot{\mathbf{X}}_{k+1}^{\mathrm{d}}={ }_{\mathrm{sl}} \ddot{\mathbf{X}}_{k+1}^{\mathrm{d} *} \quad$ (i.e. \|\|$_{\mathrm{sl}} \ddot{\mathbf{X}}_{k+1}^{\mathrm{d}}-{ }_{\mathrm{sl}} \ddot{\mathbf{X}}_{k+1}^{\mathrm{d} *} \| \leqslant \varepsilon_{a}$ ). Once this convergence is reached, Eqs. (9) and (10) (both for the sliding and the stuck components) are fulfilled. Hence, the fulfilment at instant $k+1$ of all the involved

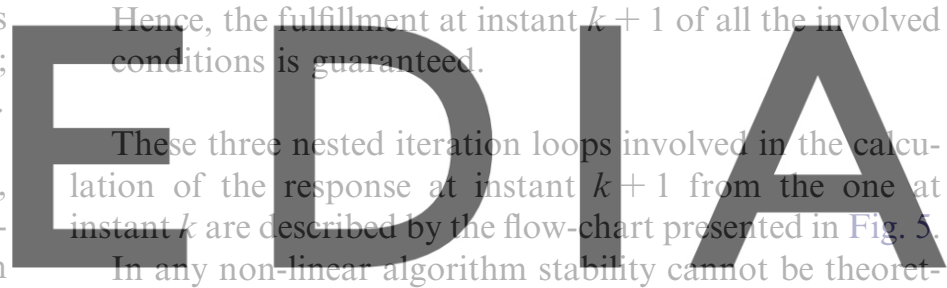

ically demonstrated; moreover, stability in the linearized

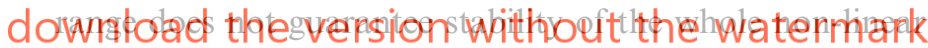
process. Hence, the time increment is basically selected by a

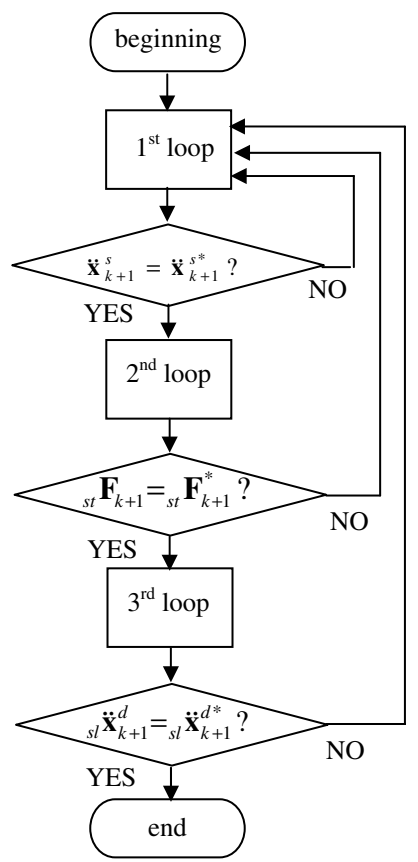

Fig. 5. Flow-chart of the proposed algorithm. 
trial and error procedure aiming to avoid numerical instabilities and inaccuracies. Convergence tolerances $\varepsilon_{a}$ and $\varepsilon_{f}$ are selected to obtain the desired degree of accuracy with a reasonable number of iterations. In most of the cases: $\Delta t=T_{\mathrm{F}} / 200, \varepsilon_{a}=\left|\ddot{x}_{\mathrm{g}}\right|_{\max } / 10^{5}$ and $\varepsilon_{f}=\mu N / 10^{5} . T_{\mathrm{F}}$ is the fundamental period of the bare frame. To select such short time steps lessens the need of checking the sliding-sticking conditions inside the time interval.

\section{Examples}

This section presents some results from the proposed algorithm.
Figs. 6 and 7 show a pair of time history responses of a single story frame $(N=1)$ equipped with a friction dissipator (see Fig. 1). Mass, damping and stiffness structural parameters are $m=5740.39 \mathrm{~kg}, \quad c=13121.77 \mathrm{~N} \mathrm{~s} / \mathrm{m}$ (modal damping ratio $\zeta=0.05$ ) and $k=2999.471 \mathrm{kN} / \mathrm{m}$, respectively. The corresponding parameters of the bracing system are $m^{\prime}=19.614 \mathrm{~kg}, \quad c^{\prime}=0 \quad\left(\zeta^{\prime}=0\right) \quad$ and $\quad k^{\prime}=$ $2597.01 \mathrm{kN} / \mathrm{m}$. The sliding threshold is $\mu N=39.325 \mathrm{kN}$; this value has been selected trying to optimize the reduction of the response of the frame to a wide set of excitations [9].

Fig. 6 shows the free response starting from an initial displacement $x_{0}=x_{0}^{\prime}=10 \mathrm{~cm}$. Fig. 7 shows the forced response for a harmonic driving force applied to the main

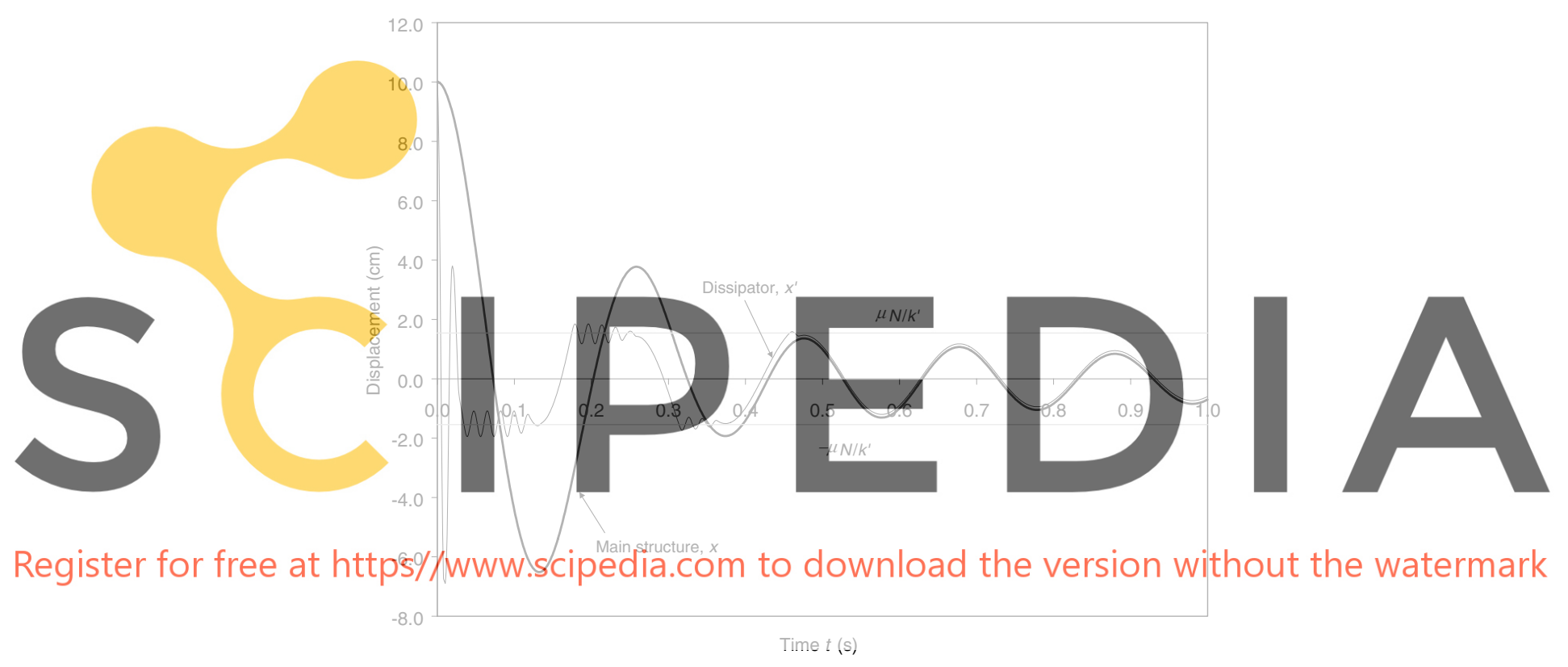

Fig. 6. Time-history response of a single-story building for an initial displacement.

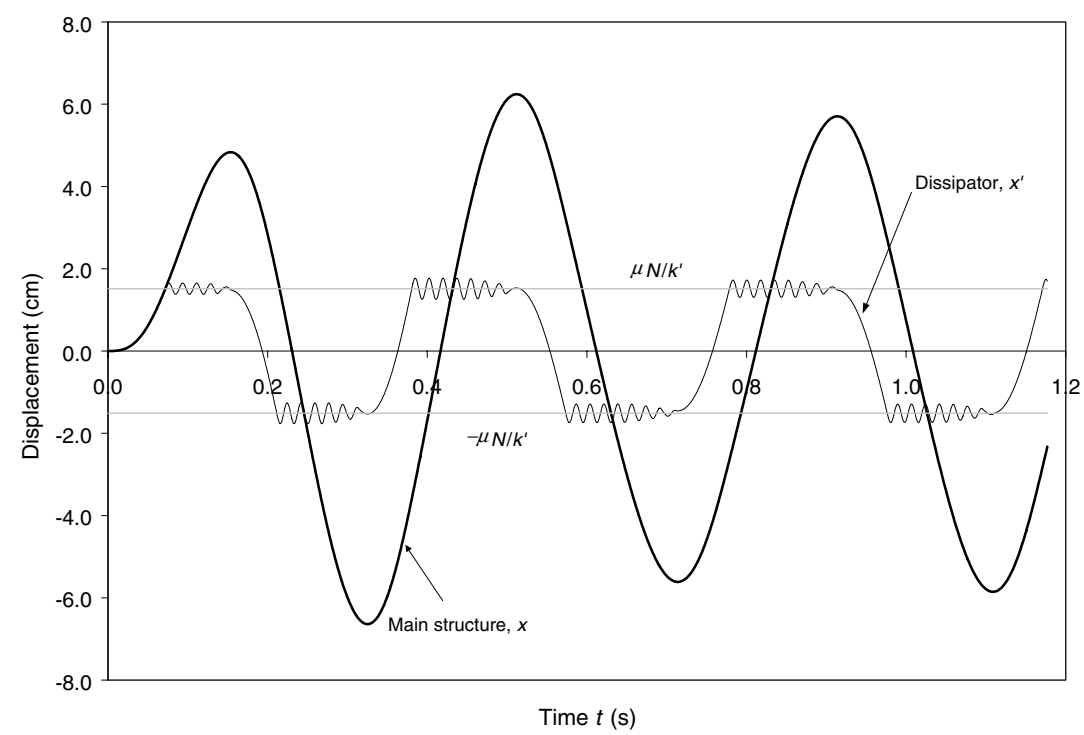

Fig. 7. Time-history response of a single-story building for a harmonic driving force. 
frame; the input amplitude is $127.491 \mathrm{kN}$ while its frequency is $15.9781 \mathrm{rad} / \mathrm{s}$.

In Figs. 6 and 7 the thick and thin lines correspond to the main frame and the dissipator displacements, respectively. The upper and lower horizontal lines correspond to the thresholds $\mu N / k^{\prime}$ and $-\mu N / k^{\prime}$, respectively. These values limit the displacement $x^{\prime}$ of the dissipator [16] (since, if $\left|x^{\prime}\right|>\mu N / k^{\prime}$, sliding begins); the oscillations observed in Figs. 6 and 7 around the horizontal lines $x= \pm \mu N / k^{\prime}$ are due to the inertial forces generated by the mass $m^{\prime}$ of the
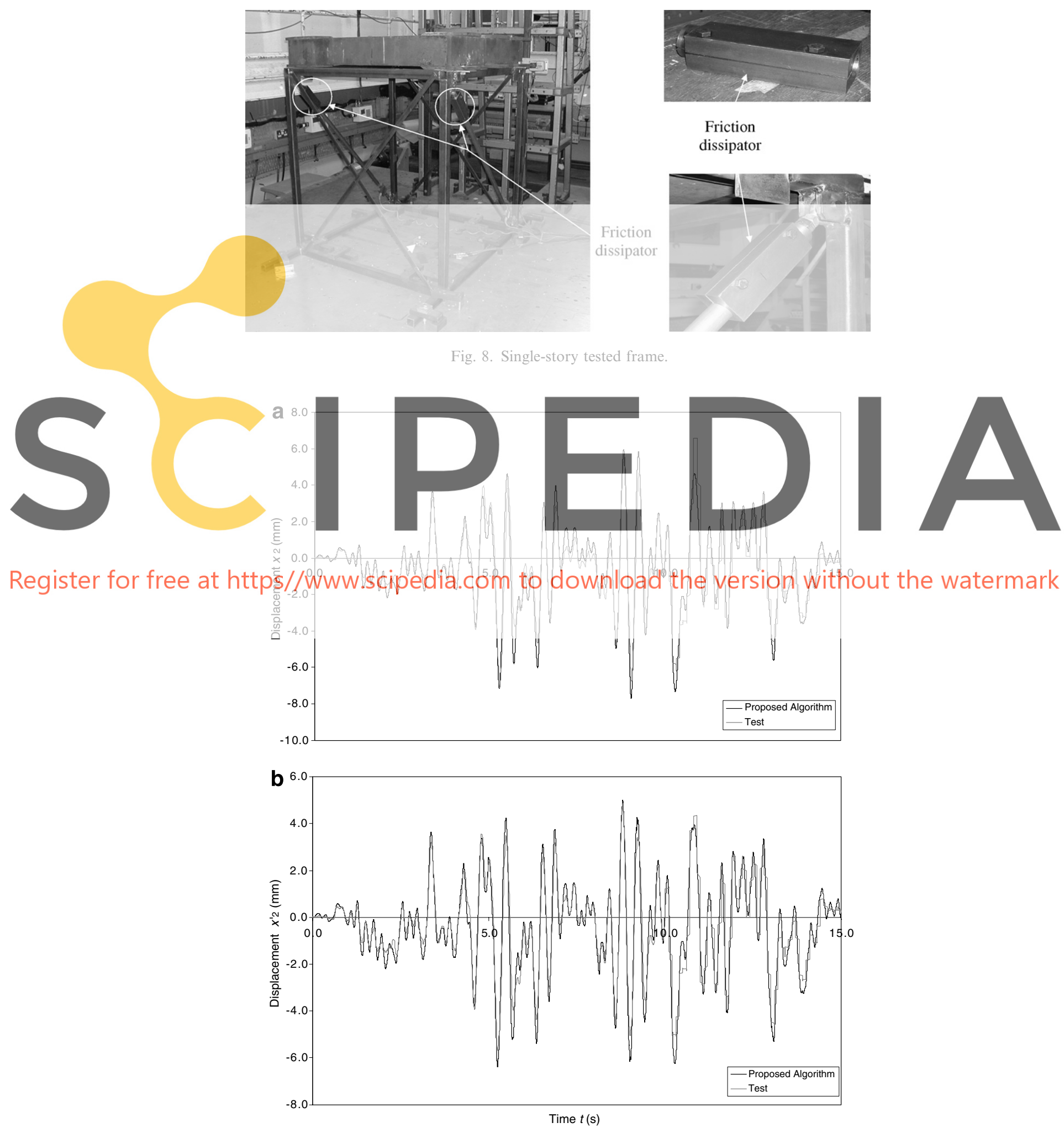

Fig. 9. Comparison between numerical and experimental second floor displacements. (a) Second floor (main frame), (b) second floor (dissipator). 

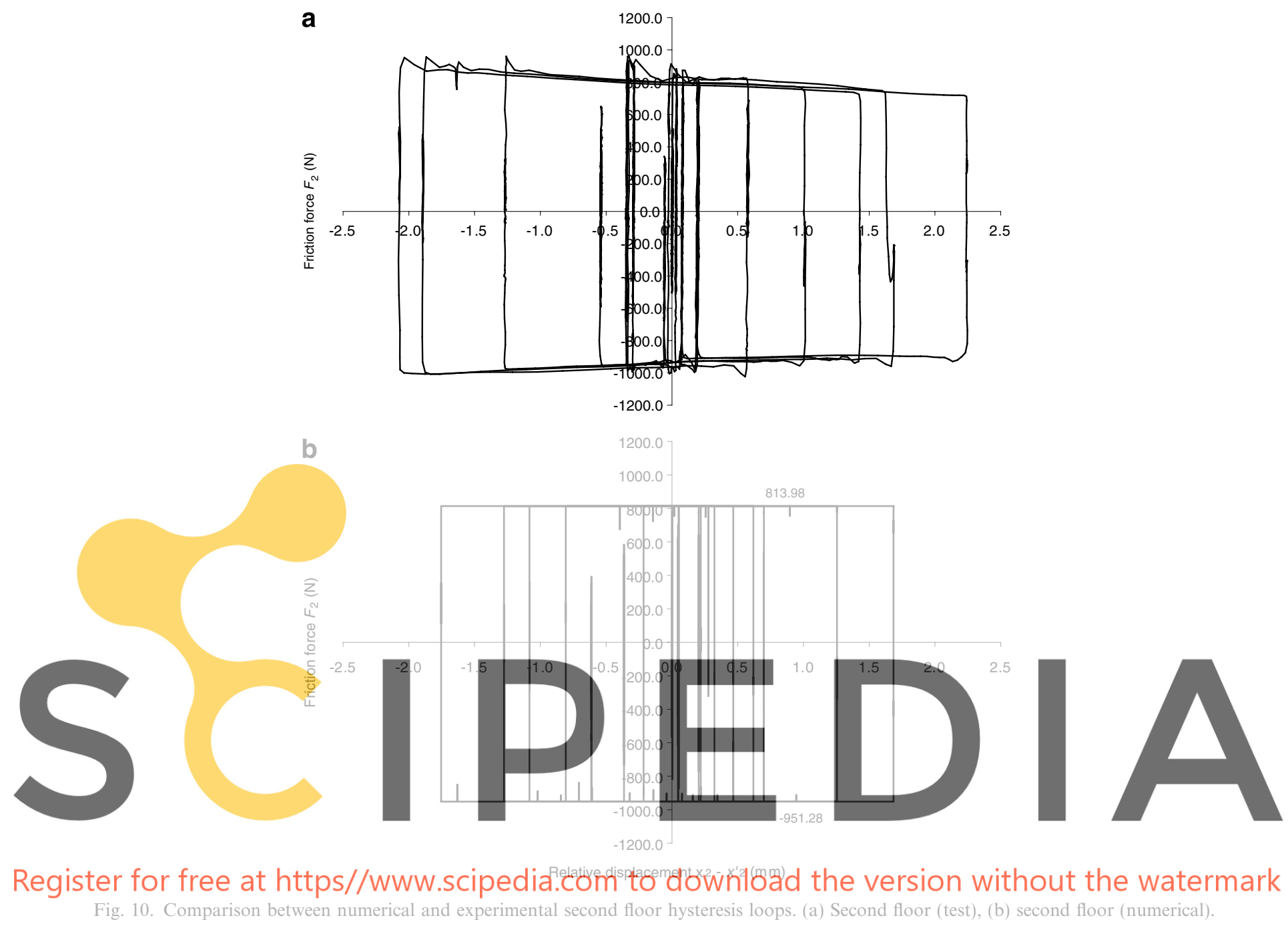

bracing; obviously, the smaller the values of $m^{\prime}$, the lesser the oscillation amplitudes of $x^{\prime}$ around these thresholds.

Plots in Fig. 6 seem to show a significant increase in the damping capacity of the structure due to the contribution of the dissipators; however this effect disappears once sliding finishes (for $t=0.48 \mathrm{~s}$, approximately). The large displacement peak in the dissipator $\left(x^{\prime}\right)$ at the beginning of the time history has no particular structural significance as is an inertial effect due to the mass of the dissipator $\left(\mathrm{m}^{\prime}\right)$. Plots in Fig. 7 indicate that there is sliding and, hence, a significant amount of input energy is dissipated.

\section{Comparison with experimental results}

As mentioned previously, this work belongs to a bigger research project [9] that involves testing. This section presents some comparisons between such experimental results and the simulated ones (with the proposed software code).

The experiments consisted of applying horizontal unidirectional seismic inputs to two reduced-scale steel laboratory models of building structures (with one and two floors, respectively) which incorporate friction dissipators.
A full description can be found in [9]; Fig. 8 shows pictures of the tested single-story frame (left) and of the friction dissipators (right).

Figs. 9 and 10 present some comparisons between numerical and experimental results for the two-story model. The driving input is the Northridge earthquake (Santa Monica station, $90^{\circ}$ component, January 17, 1994).

Fig. 9 displays the time history displacement responses of the second floor main frame (top, a) and dissipator (bottom, b). The thick line corresponds to numerical results while the thin one corresponds to experimental ones. Fig. 10 displays the second floor hysteresis loops. The top plots (a) are experimental while the bottom ones (b) are numerical.

Plots from Fig. 9 show a good agreement between numerical and experimental results. Conversely, the upper plots in Fig. 10 show that the actual behavior of the dissipators does not correspond to a Coulomb model since the hysteresis loops are neither rectangular (the top and bottom branches are not horizontal) nor vertically centered (the maximum and minimum values of the friction force are not equal to $\pm \mu N$, respectively). As the proposed algo- 
rithm considers only simple dry friction laws with constant friction coefficients (velocity independent), the first of these two circumstances cannot be accounted for in the simulation. Despite these limitations, the agreement between numerical and experimental results is satisfactory. Similar conclusions can be derived form the other comparisons in the other tests; it shows that the proposed algorithm is accurate and reliable.

\section{Comparison with results from other codes}

There are currently a certain number of numerical simulations of structures equipped with friction dissipators $[23,20,13]$. In order to carry out the numerical simulation, some computer programs have been written specifically with this purpose $[10,13,29]$ while others use commercial software packages such as DRAIN-2D [11,22,1,6], DRAIN-TABS [23], SADSAP [12], SAP2000NL [19] or ADINA [3]

Basically, the existing models fall into one of these two categories:

- Models where the dynamic behavior of the friction dis-

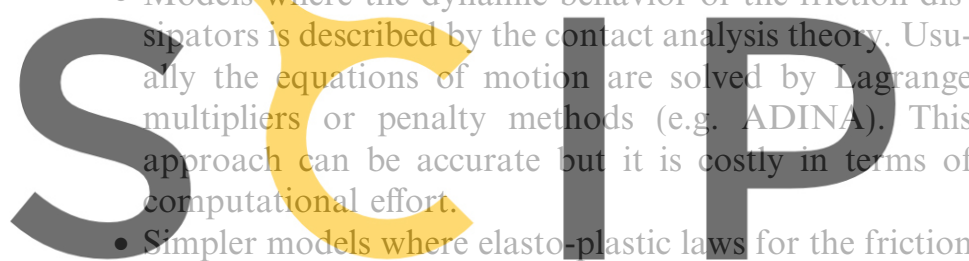

dissipators are implemented in finite element models of Regist the whole structure (DRAIN-2D, DRAINTABS,

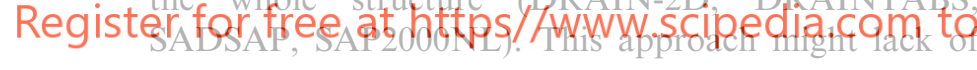
accuracy.

As discussed previously, the proposed algorithm tries to overcome the limitations of both approaches, i.e. it is intended to be accurate and reliable yet computationally efficient. This last capacity can be particularly relevant for parametric assessments, as a large number of numerical simulations are involved.

To confirm these asserts and to further demonstrate the accuracy and reliability of the proposed algorithm, some comparisons between their results and those arising from commercial packages are presented in this section. Two buildings with 3 and 10 stories, respectively, are subjected to seismic inputs. Both cases are described next.

The first case is a three-story, four-bay steel frame. To obtain reliable conclusions, the considered building is based on a benchmark problem for any vibration control system [27]. Steel braces are further incorporated at each floor to support three friction dampers as shown in Fig. 11.

In the benchmark building the cross sections of the braces are $118.71 \mathrm{~cm}^{2}\left(10^{\prime \prime} \times 10^{\prime \prime} \times 0.5^{\prime \prime}\right.$ square hollow tube). The braces are assumed to work both in tension and compression (i.e. no buckling). By using standard 2D lumped masses models (usual in earthquake engineering), the mass, stiffness and damping matrices are

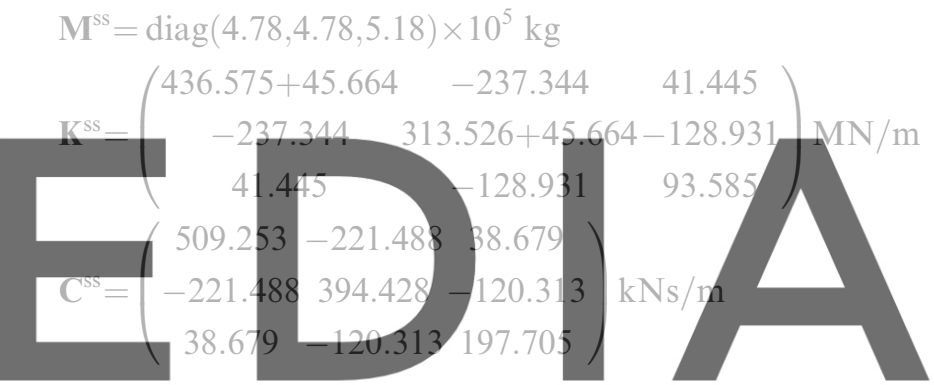

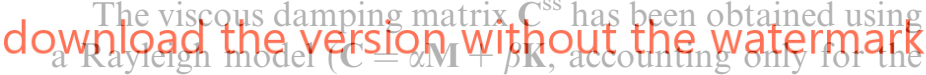
terms corresponding to the main frame) where $\alpha=0.213$ and $\beta=9.33 \times 10^{-4}$. The resulting modal damping factors are $\zeta_{1}=0.02, \zeta_{2}=0.01451$ and $\zeta_{3}=0.02$; and the three natural periods of the bare frame are $T_{1}=1.01 \mathrm{~s}, T_{2}=$ $0.33 \mathrm{~s}$ and $T_{3}=0.17 \mathrm{~s}$. The mass and stiffness matrices for the bracing system are

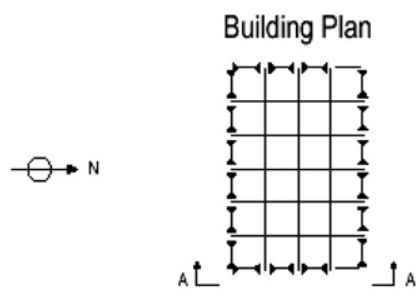

Elevation

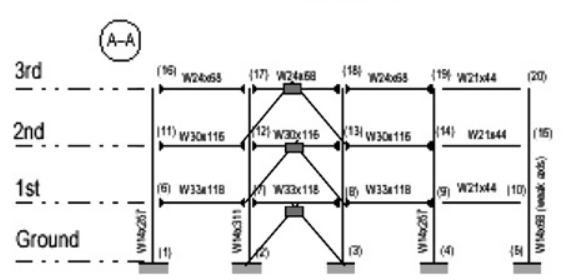

\begin{tabular}{|c|c|}
\hline NO & \\
\hline $\begin{array}{l}\text { Beams ( } 248 \mathrm{MPa} \text { ): } \\
\text { beam sizes as indicat }\end{array}$ & figure. \\
\hline Columns (345 MPa): & \\
\hline column sizes same th & hout elevation. \\
\hline Restraints: & \\
\hline columns fixed at base & \\
\hline Connections: & \\
\hline $\begin{array}{l}-\rightarrow \text { indicates a mom } \\
-- \text { indicates a simpl }\end{array}$ & $\begin{array}{l}\text { esisting connection; } \\
\text { nged) connection. }\end{array}$ \\
\hline $\begin{array}{l}\text { Dimensions: } \\
\quad \text { all measurements are }\end{array}$ & ter line; \\
\hline floor-to-floor heights & $3.96 \mathrm{~m}\left(13^{\prime}-0^{\prime \prime}\right)$ \\
\hline bay widths (all) & $9.15 \mathrm{~m}\left(30^{\prime}-0^{\prime \prime}\right)$. \\
\hline $\begin{array}{l}\text { Seismic Mass: } \\
\text { including steel framin }\end{array}$ & both N-S MRFs; \\
\hline 1st-2nd levels & $9.57 \times 10^{5} \mathrm{~kg}$ \\
\hline 3rd level & $1.04 \times 10^{6} \mathrm{~kg}$ \\
\hline entire structure & $2.95 \times 10^{6} \mathrm{~kg}$. \\
\hline
\end{tabular}

Fig. 11. Benchmark building with a friction dissipator per floor. 
$\mathbf{M}^{\mathrm{dd}}=\operatorname{diag}(350.11,350.11,350.11) \mathrm{kg}$

$\mathbf{K}^{\mathrm{dd}}=\operatorname{diag}(448.12,448.12,448.12) \mathrm{MN} / \mathrm{m}$

Viscous damping in the bracing (frame supporting the dissipators) is neglected: $\mathbf{C}^{\mathrm{dd}}=\mathbf{0}$. Comparison among the masses of the main structure $\left(\mathbf{M}^{\mathrm{ss}}\right)$ and of the bracing system $\left(\mathbf{M}^{\mathrm{dd}}\right)$ shows that this last is not completely negligible. The sliding thresholds are $\mu_{1} N_{1}=834.095 \mathrm{kN}, \mu_{2} N_{2}=$ $740.831 \mathrm{kN}$ and $\mu_{3} N_{3}=437.510 \mathrm{kN}$; these values have been selected trying to reduce the interstory drift for a wide set of inputs [9].

Fig. 12 shows a comparison between the time histories of the third floor relative displacement calculated using ADINA and the proposed algorithm. The seismic input is the Northridge earthquake, Sylmar County Hospital register (17 January, 1994, $90^{\circ}$ ). The maximum acceleration is $0.604 \mathrm{~g}$. Only the first $10 \mathrm{~s}$ of the record are considered for the analysis.
The plots from Fig. 12 show a good agreement between both numerical models. The energy dissipated by friction is $1350 \mathrm{~kJ}$, the energy dissipated by viscous damping is $219 \mathrm{~kJ}$ and the input energy is $1640 \mathrm{~kJ}$; they are slightly unbalanced because the kinetic and strain energies are not zero at the end of the displayed time interval. Similar values are obtained from ADINA.

Fig. 13 compares the third floor displacement time histories with and without dissipators $\left(\mu_{i} N_{i}=0\right)$.

Plots in Fig. 13 highlight the reduction in the structural response due to the dissipative effect of the friction devices.

A comparison between the performances of the proposed algorithm and of ADINA has been carried out. In virtually all of the considered cases significant differences have been found showing that the proposed code is faster and requires less memory allocation. A description of an illustrative example is described next. The structure considered for the simulation is the benchmark building of

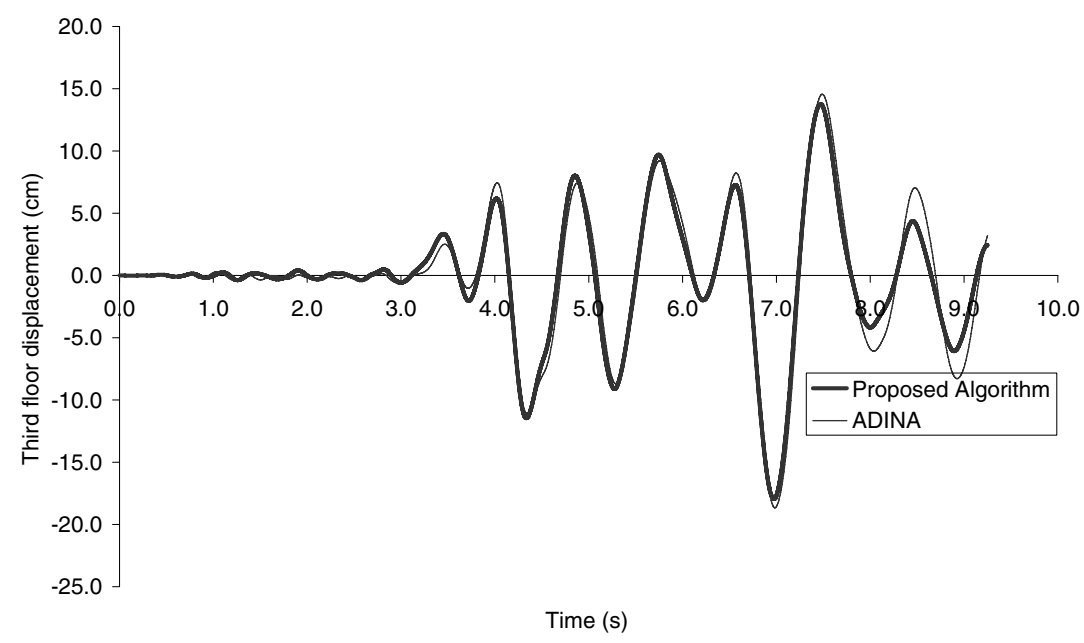

Fig. 12. Comparison between the third floor displacements calculated with ADINA and with the proposed algorithm. Benchmark building.

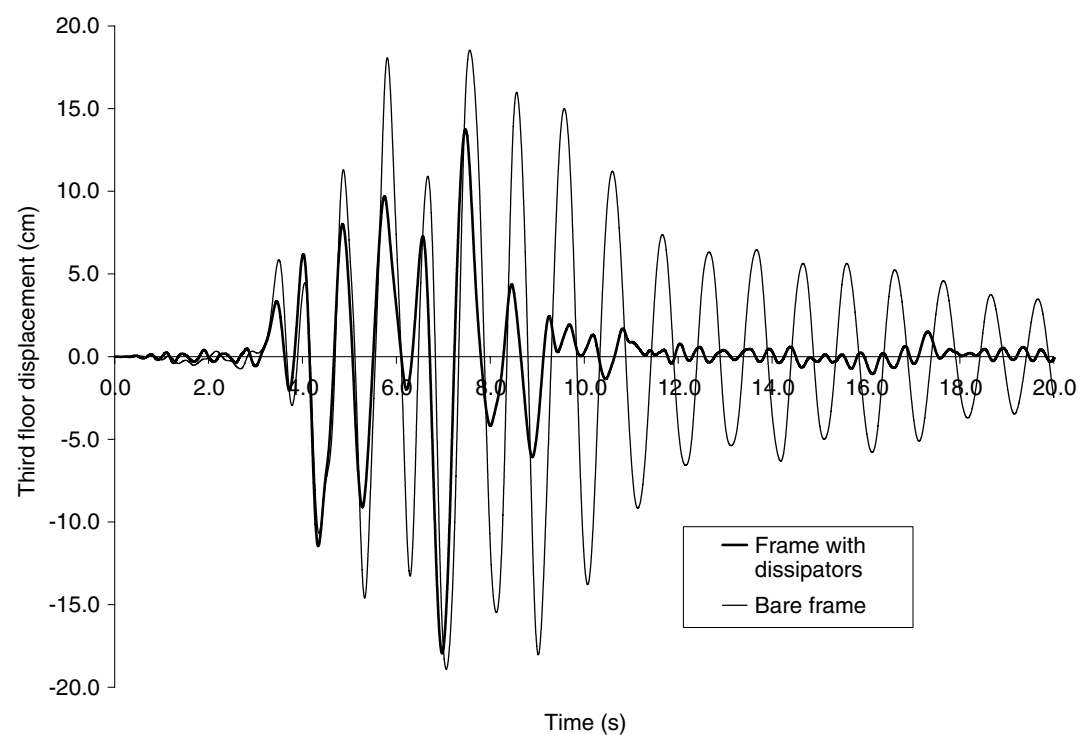

Fig. 13. Comparison between the third floor displacements of the bare frame and of the frame protected with dissipators. Benchmark building. 
Fig. 10. The building is subjected to a seismic input of $15 \mathrm{~s}$ of duration. The main features of the computer machine used in this test are: Pentium II processor at $233 \mathrm{MHz}$ and $96 \mathrm{MB}$ RAM. In order to get comparable results no additional software has been running at the same time. For both programs, the lengths of the discretization periods have been chosen as long as possible to obtain enough stability and accuracy. For ADINA the CPU time was $15 \mathrm{~min}$ and $500 \mathrm{MB}$ HD memory was required, while for the proposed algorithm the CPU time was $3 \mathrm{~min} 20 \mathrm{~s}$ and no significant memory allocation was necessary. For further details, the system monitors for both programs are displayed in Fig. 14. It is remarkable that a general purpose 3D non-linear FE commercial package should take more resources to initialize internal variables and to perform calculations using 3D computational algorithms than a code which has been specifically designed to solve a particular 2D problem.
The other analyzed structure consists of a 10-story building equipped with friction dissipators in each floor (see Fig. 1(a)). The values of matrices $\mathbf{M}^{\mathrm{ss}}$, and $\mathbf{K}^{\mathrm{ss}}$ can be found in the reference by Levy et al. [18]. Matrix $\mathbf{C}^{\text {ss }}$ was calculated considering all the modal damping ratios $\zeta_{i}=0.02$. Matrices $\mathbf{M}^{\mathrm{dd}}$ and $\mathbf{C}^{\mathrm{dd}}$ were considered null; $\mathbf{K}^{\mathrm{dd}}$ was determined using the coefficients given in [18]. The values of the sliding thresholds, $\mu_{i} N_{i}$, are also given in [18]. The seismic input is El Centro earthquake, N-S component, $\mathrm{PGA}=0.40 \mathrm{~g}$.

Fig. 15 shows a comparison between the top floor response obtained using the proposed algorithm (black) and the one displayed in [18] (grey). The driving force is also shown.

The difference between both plots in Fig. 15 might be due to the different numerical models employed, since in [18] an elastic-perfectly plastic law is used while the proposed model relies on a formulation more suitable for

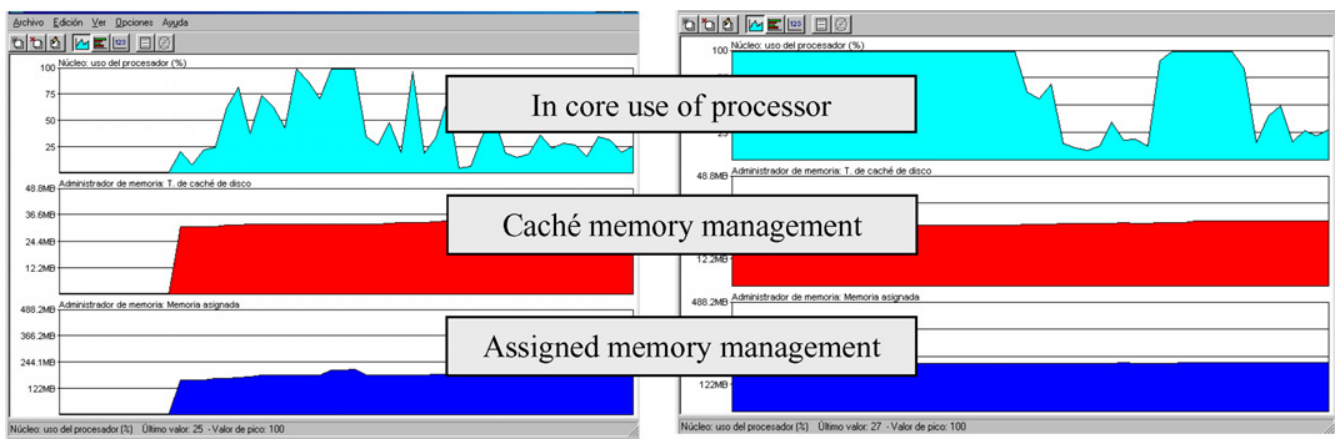

Fig. 14. Comparison between the system monitors for the proposed algorithm (left) and for ADINA (right). Benchmark building.

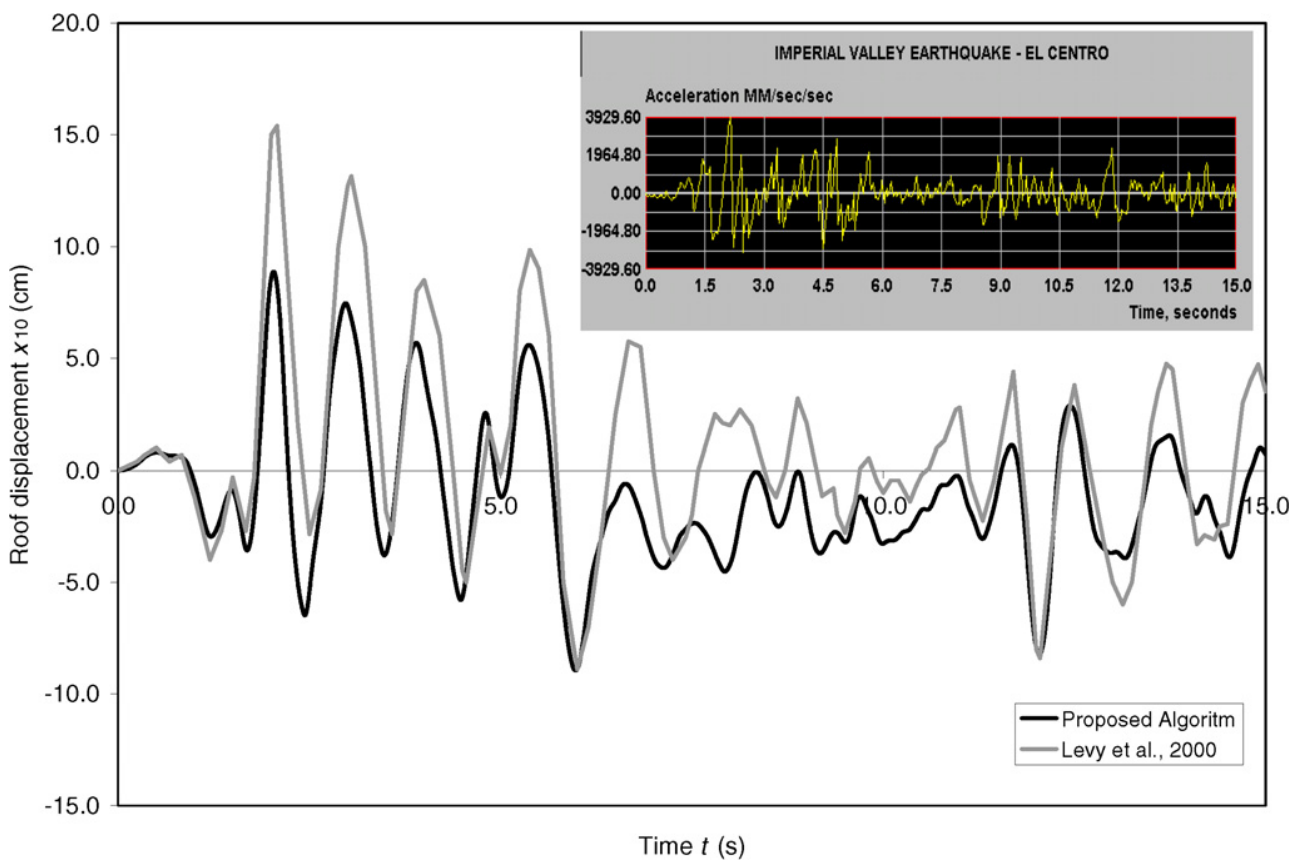

Fig. 15. Comparison between the upper floor displacements calculated by Levy et al. and computed with the proposed algorithm. 10-story building. 
friction simulation. It is remarkable that the main divergencies start when big displacements (generating non-linear behavior) arise for the first time.

\section{Conclusions and future research}

This paper presents a numerical model of the dynamic behavior of 2D $N$-story frames modelled as $N$-DOF systems that incorporate friction energy dissipators. This model can be also used for buildings with friction isolators. The non-linear equations of motion are solved numerically by a step-by-step algorithm developed by the authors, which is based on the linear acceleration method. The main innovation consists of checking at each calculation instant the sliding or sticking condition at each floor; hence, the number of "active" degrees of freedom changes continuously, ranging in between $N$ (there is sticking condition at every dissipator) and $2 N$ (there is sliding condition at every dissipator). This procedure provides results that are close to those obtained with the ADINA package (yet being more computationally efficient) and to experimental results.

A parametric study about structures that incorporate this type of passive damper is currently being carried out. This research incorporates experimental testing to further validate the proposed algorithm. Initial studies tend to show that dissipators significantly reduce the response of the structure.

\section{Acknowledgments}

This work has received financial support from the Spanish Government (DGICYT), Research Projects No. PB980455, REN2000-1740-C05-01 and REN2001 - 241840. The stay of Mr. De la Cruz in Barcelona was funded by the Council of Science and Technology (CONACYT) of Mexico, Grant No. 116708/117876. Finally, the authors wish to thank the Geotechnical Engineering and Geo-Sciences Department of the Technical University of Catalonia and to the Civil and Environmental Engineering Department of the Universidad Autónoma de Ciudad Juárez for their support.

\section{References}

[1] Baktash P, Marsh C. Damped moment-resistant braced frames: a comparative study. Can J Civil Eng 1987;14:342-6.

[2] Barbat AH, Bozzo LM. Seismic analysis of base isolated buildings. Arch Comput Methods Eng 1997;4(2):153-92.

[3] Bathe KJ. Finite element procedures in engineering analysis. Prentice-Hall; 1982.

[4] Berg G. Elements of structural dynamics. Prentice-Hall; 1989.

[5] Charney FA. Nonlinear dynamic time history analysis of single degree of freedom systems (NONLIN). Federal Emergency Management Agency (FEMA). Available from: http://training.fema.gov/ EMIWeb/nonlin.htm, 1996.
[6] Cherry S, Filiatrault A. Seismic response control of buildings using friction dampers. Earthquake Spectra 1993;9(3):447-66.

[7] Clough R, Penzien J. Dynamics of structures. McGraw-Hill; 1992.

[8] De la Cruz ST, López Almansa F, Bozzo LM, Pujades LG. Dynamic equivalence between a SDOF bi-linear structure and a SDOF structure equipped with an energy dissipation device of friction. In: Third World Conference on Structural Control, Como, Italy, 2002.

[9] De la Cruz ST. Contribution to the assessment of the efficiency of friction dissipators for seismic protection of buildings. Ph.D. Thesis, Technical University of Catalonia, Barcelona, 2003.

[10] Filiatrault A, Cherry S. Performance evaluation of friction damped braced steel frames under simulated earthquake loads. Earthquake Spectra 1987;3(1):57-78.

[11] Filiatrault A, Cherry S. Efficient numerical modelling for the design of friction damped braced steel plane frames. Can J Civil Eng 1989;42:211-8.

[12] Foti D, Bozzo LM, López Almansa F. Numerical efficiency assessment of energy dissipators for seismic protection of buildings. Earthquake Eng Struct Dyn 1998;27:543-56.

[13] Grigorian CE, Yang TS, Popov EP. Slotted bolted connection energy dissipators. Earthquake Spectra 1993;9(3):491-504.

[14] Hanson R, Aiken I, Nims D, Richter P, Bachman R. State of the art of the practice in seismic energy dissipation. In: Proceedings of ATC $17-1$ on seismic isolation, energy dissipation, and active control 2;1993:449-71.

[15] Housner GW, Bergman LA, Caughey TK, Chassiakos AG, Claus RO, Masri SF, et al. Structural control: past, present and future. J Eng Mech, ASCE 1997;123(2):897-971.

[16] Humar JL. Dynamics of structures. Prentice-Hall; 1990.

[17] Kelly JM. Earthquake-resistant design with rubber. Springer-Verlag; 1993.

[18] Levy R, Marianchik E, Rutenberg A, Segal F. Vibration control of structures under earthquake loading by three-state friction-grip elements. Earthquake Eng Struct Dyn 2000;29:1569-85.

[19] Naeim F, Kelly JM. Design of seismically isolated structures: from theory to practice. John Wiley; 1999.

[20] Nims DK, Richter PJ, Bachman RE. The use of the energy dissipating restraint for seismic hazard mitigation. Earthquake Spectra 1993;9(3):467-90.

[21] Oliver J, Oller S, Cante JC. Numerical simulation of uniaxial compaction processes in powder materials. In: International congress on numerical methods in engineering, Chile, 1992.

[22] Pall A, Marsh C. Response of friction damped braced frames. ASCE J Struct Div 1982;108(6):1313-23.

[23] Pall A, Vezina S, Prouxl P, Pall R. Friction-dampers for seismic control of Canadian space agency headquarters. Earthquake Spectra 1993;9(3):547-57.

[24] Richter PJ, Nims DK, Kelly JM, Kallembach RM. The EDR energy dissipating restraint. A new device for mitigation of seismic effects. In: Proceedings of the 1990 SEAOC convention 1;1990:377401.

[25] Simo JC, Hughes TJR. Computational inelasticity. Springer-Verlag; 1999.

[26] Soong TT, Dargush GF. Passive energy dissipation systems in structural engineering. John Wiley \& Sons; 1997.

[27] Spencer BF, Christenson RE, Dyke SJ. Next generation benchmark control problems for seismically excited buildings. In: 2nd World conference on structural control, Kyoto, Japan 2;1999:1135-1360.

[28] Vezina S, Proulx P, Pall R, Pall A. Friction-dampers for a seismic design of Canadian space agency. In: 10th World conference on earthquake engineering, Madrid, 1992. p. 4123-8.

[29] Vulcano A, Mazza F. Seismic analysis and design of RC frames with dissipative devices. In: 11th European conference on earthquake engineering, Rotterdam, 1992. 